\title{
Electromagnetic energy deposition rate in the polar upper thermosphere derived from the EISCAT Svalbard radar and CUTLASS Finland radar observations
}

\author{
H. Fujiwara ${ }^{1}$, R. Kataoka ${ }^{2}$, M. Suzuki ${ }^{1}$, S. Maeda ${ }^{3}$, S. Nozawa $^{4}$, K. Hosokawa ${ }^{5}$, H. Fukunishi ${ }^{1}$, N. Sato ${ }^{6}$, and \\ M. Lester ${ }^{7}$ \\ ${ }^{1}$ Department of Geophysics, Graduate School of Science, Tohoku University, Sendai, Japan \\ ${ }^{2}$ RIKEN (The Institute of Physics and Chemical Research), Saitama, Japan \\ ${ }^{3}$ Faculty for the Study of Contemporary Society, Kyoto Women's University, Kyoto, Japan \\ ${ }^{4}$ Solar-Terrestrial Environment Laboratory, Nagoya University, Nagoya, Japan \\ ${ }^{5}$ The University of Electro-Communications, Tokyo, Japan \\ ${ }^{6}$ National Institute of Polar Research, Tokyo, Japan \\ ${ }^{7}$ Department of Physics and Astronomy, University of Leicester, Leicester, UK
}

Received: 23 October 2006 - Revised: 5 October 2007 - Accepted: 14 November 2007 - Published: 29 November 2007

\begin{abstract}
From simultaneous observations of the European incoherent scatter Svalbard radar (ESR) and the Cooperative UK Twin Located Auroral Sounding System (CUTLASS) Finland radar on 9 March 1999, we have derived the height distributions of the thermospheric heating rate at the $\mathrm{F}$ region height in association with electromagnetic energy inputs into the dayside polar cap/cusp region. The ESR and CUTLASS radar observations provide the ionospheric parameters with fine time-resolutions of a few minutes. Although the geomagnetic activity was rather moderate $\left(K p=3^{+} \sim 4\right)$, the electric field obtained from the ESR data sometimes shows values exceeding $40 \mathrm{mV} / \mathrm{m}$. The estimated passive energy deposition rates are also larger than $150 \mathrm{~W} / \mathrm{kg}$ in the upper thermosphere over the ESR site during the period of the enhanced electric field. In addition, enhancements of the Pedersen conductivity also contribute to heating the upper thermosphere, while there is only a small contribution for thermospheric heating from the direct particle heating due to soft particle precipitation in the dayside polar cap/cusp region. In the same period, the CUTLASS observations of the ion drift show the signature of poleward moving pulsed ionospheric flows with a recurrence rate of about $10-20 \mathrm{~min}$. The estimated electromagnetic energy deposition rate shows the existence of the strong heat source in the dayside polar cap/cusp region of the upper thermosphere in association with the dayside magnetospheric phenomena of reconnections and flux transfer events.
\end{abstract}

Keywords. Ionosphere (Ionosphere-atmosphere interactions; Polar ionosphere) - Magnetospheric physics (Polar cap phenomena)

Correspondence to: $\mathrm{H}$. Fujiwara

(fujiwara@pat.geophys.tohoku.ac.jp)

\section{Introduction}

Various ionospheric and auroral phenomena due to the interaction between the solar wind and the magnetosphere have been observed in the dayside polar cap/cusp region. The polar patches, the pulsed ionospheric flows, and the poleward-moving radar auroral forms are well-known phenomena (e.g., Basu and Valladares, 1999; Provan et al., 1999; Wild et al., 2001, and references therein). In addition, traveling ionospheric disturbances (TIDs) caused by various forcings have been frequently observed in the polar cap region (e.g., Macdougall et al.,2001; Prikryl et al., 2005). These ionospheric and auroral phenomena indicate the presence of various energy inputs into the dayside polar cap/cusp region and heating processes for not only plasmas in the ionosphere but also neutrals in the thermosphere.

The variability of the convection electric field has been recognized to be one of the most important issues of the polar ionospheric/thermospheric physics since Codrescu et al. (1995) pointed out that the electric field fluctuation with time-scale of several minutes contributes to Joule heating. Codrescu et al. (2000) and Matsuo et al. (2002) derived binaveraged maps of the electric field variability from incoherent scatter radar data and the Dynamics Explorer 2 (DE2) satellite data, respectively. Matsuo et al. (2002) used an empirical orthogonal function (EOF) analysis to show that the first two EOFs were related to the variability associated with the interplanetary magnetic field (IMF) and the third to the variability in the cusp region.

Shepherd et al. (2003) showed temporal variability of the ionospheric convection from direct measurements with the Super Dual Auroral Radar Network (SuperDARN) radars. They found two distinct regions of variability of the

Published by Copernicus Publications on behalf of the European Geosciences Union. 

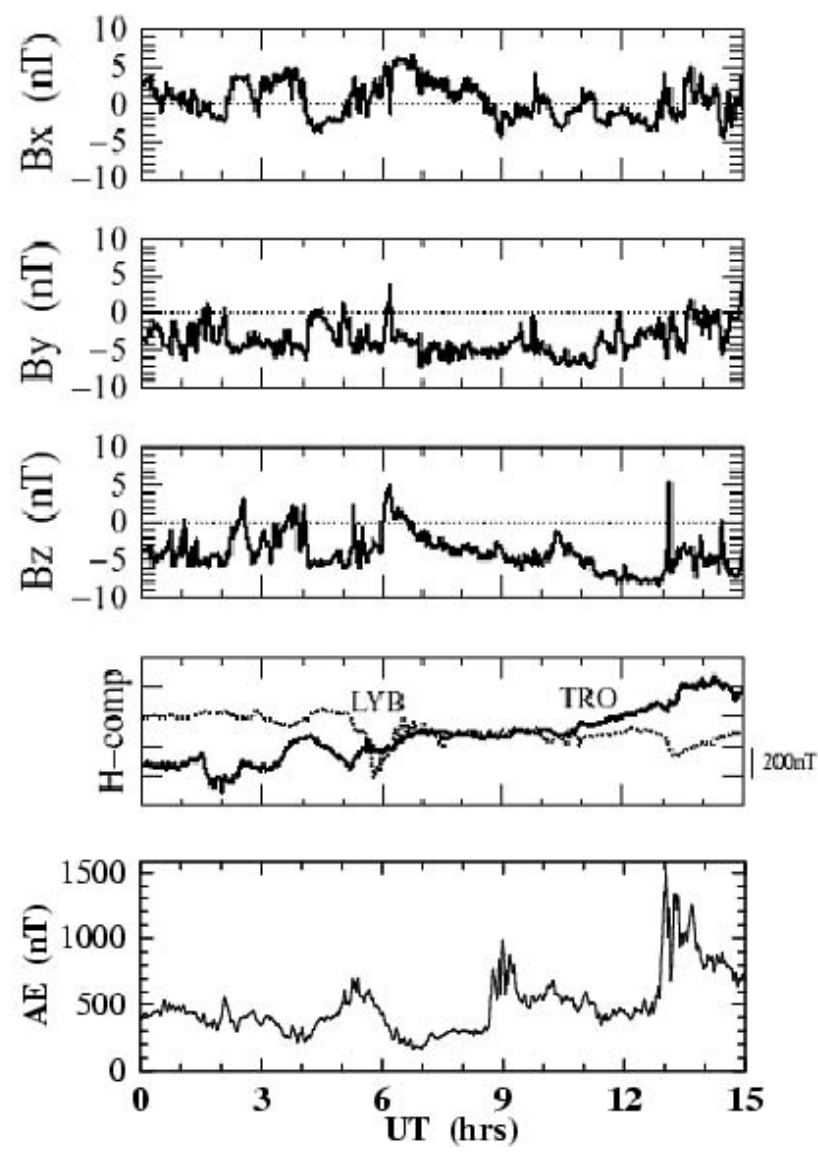

Fig. 1. The IMF $B_{x}, B_{y}$, and $B_{z}$ components measured by the WIND spacecraft upstream in the solar wind, H-component of the geomagnetic field at Troms $\varnothing$ (TRO) and Longyearbyen (LYB) and the quick-look AE index on 9 March 1999, from top to bottom.

ionospheric convection and plasma flow: the region near the dayside dusk convection reversal boundary characterized by large $(>1 \mathrm{~km} / \mathrm{s})$ and rapid $(<2 \mathrm{~min})$ fluctuations in line-ofsight velocity and the region at the higher latitudes in the convection throat characterized by relatively uniform flow over the polar cap at roughly $600 \mathrm{~m} / \mathrm{s}$. Using data obtained from the satellite CHAMP (Challenging Mini-satellite Payload) observations, Lühr et al. (2004) showed thermospheric density enhancements of almost a factor of two at about $450 \mathrm{~km}$ altitude when the satellite passed the cusp region. They also found indications of enhanced small-scale field aligned currents observed simultaneously with the density enhancements and suggested atmospheric up-welling caused by local Joule heating in the cusp region.

These features of the electric field variations and/or the small-scale field aligned currents suggest electromagnetic energy deposition which results in various dynamical processes in the dayside polar cap/cusp region. Maeda et al. $(2002,2005)$ showed that the dayside $\mathrm{E}$ region ion and neutral temperatures at Longyearbyen were higher than those at Troms $\varnothing$ with the European incoherent scatter (EISCAT) radars. They suggested the heat transport by the polar neutral winds in addition to Joule and/or auroral particle heating for causing the high temperatures in the polar cap/cusp E region. Fujiwara et al. (2004) estimated the electromagnetic and turbulent energy dissipation rates in the lower thermosphere using the EISCAT Svalbard radar (ESR) at Longyearbyen. They showed that, on the average, the electromagnetic and turbulent energy dissipations were dominant above and below about $110 \mathrm{~km}$, respectively. The energetics of neutral gases in the $\mathrm{E}$ region/lower thermosphere has been often investigated (e.g., Fujii et al., 1999; Thayer, 2000), while studies of the $\mathrm{F}$ region/upper thermosphere were quite few (e.g., Wu et al., 1996; Thayer and Semeter, 2004).

In this study, we focus our attention on the electromagnetic energy input from the magnetosphere into the dayside polar cap/cusp region of the upper thermosphere. In order to observe the ionosphere with fine time-resolutions, the ESR and the Cooperative UK Twin Located Auroral Sounding System (CUTLASS) Finland radar have been used because these radars provide the ionospheric parameters with timeresolutions of a few minutes. Simultaneous observations with the ESR and CUTLASS are quite useful for studying origins of ionospheric/thermospheric variations at the F region height (e.g., Ogawa et al., 2001; Wild et al., 2001).

In the present study, the CUTLASS Finland radar observes the signatures of cusp plasma and poleward moving pulsed ionospheric flows during the period of the significant thermospheric heating observed with the ESR, suggesting a relationship between the thermospheric heating and the dayside magnetospheric phenomena. The height profiles of the neutral gas heating rate due to the electromagnetic energy deposition are presented, and the contributions of the particle precipitation, neutral density, and neutral wind in the cusp region to heating the upper thermosphere are also discussed in the following sections.

\section{Observational condition and locations of radar sites}

We investigate energy inputs into the dayside polar cap/cusp region during 06:00-12:00 UT on 9 March 1999. The indices for representing the solar and geomagnetic activities were as follows: $F_{10.7}=125 \times 10^{-22} \mathrm{~W} / \mathrm{m}^{2} / \mathrm{Hz}$ and $K p=3^{+} \sim 4$ $(A p=21)$. The interplanetary magnetic field (IMF) $B_{y}$ and $B_{z}$ components were predominantly negative for this period. Although the variations of the IMF and the geomagnetic field in this period were already shown (Maeda et al., 2002; 2005), the variations are shown again in Fig. 1. Before 06:00 UT, prominent IMF variations, which caused the magnetic field variations at Longyearbyen, are seen in the IMF $B_{x}, B_{y}$ and $B_{z}$ components. A prominent pulsation starting at about 06:20 UT is also seen in the magnetic field data at Longyearbyen. The quick-look AE index shows large enhancement at around 09:00 UT. In the present study, we focus our attention 
on the period of 06:00-12:00 UT when the IMF has small fluctuations after the large variations.

The ESR site at Longyearbyen, Svalbard is located at $78.09^{\circ} \mathrm{N}, 16.03^{\circ} \mathrm{E}\left(75.12^{\circ} \mathrm{N}, 113.00^{\circ} \mathrm{E}\right.$ in geomagnetic coordinates). The local solar time (LST) and the magnetic local time (MLT) at Longyearbyen are approximately UT +1 and $\mathrm{UT}+3$, respectively. Figure 2 indicates the location of the ESR site and the beam directions of the CUTLASS Finland radar in the geomagnetic latitude and MLT coordinate system. The field of view of the CUTLASS Finland radar consists of 16 beams (Beam 0-15), with Beam 9 over the ESR site.

Figure 3 shows the high latitude electric potential described with the Heppner-Maynard empirical electric convection field model (Heppner and Maynard, 1987) in the geomagnetic latitude and MLT coordinate system when IMF $B_{y}$ and $B_{z}$ are negative. The locations of the ESR site in the period between 06:00 and 12:00 UT (09:00 and 15:00 MLT at Longyearbyen) are shown by circle dots with numbers indicating UT. The pattern of the electric field at the ESR site inferred from the empirical model is approximately consistent with that obtained from the ESR observations. The electric field obtained from the ESR observations is shown in the following section. In the present case, the recent electric potential model developed by Weimer (2005) shows a similar pattern to the Heppner-Maynard model (see e.g., Fig. 2 of Weimer, 2005). The ESR site seems to be at around the dayside convection reversal boundary of the dusk convection cell and/or poleward of the auroral oval during the period.

\section{Observational results}

\subsection{ESR observations}

The ESR allows us to observe the ionosphere connected to several magnetospheric regions, e.g., the polar cap and cusp region, in the height range from about 100 to several hundreds of $\mathrm{km}$. The details of the radar system were described by, e.g., Wannberg et al. (1997). In the present study, we use the EISCAT Common Program 2 (CP-2) mode version L data obtained in the period of 06:00-12:00 UT on 9 March 1999. Some of the data were already presented by Maeda et al. (2002, 2005). The details of the ESR observation and the method for derivation of the ionospheric parameters are described in these papers. The ionospheric conductivity tensor is also derived from the ESR data assuming ion and neutral compositions, collision frequency between ions and neutrals, and that between electrons and neutrals in the same way as Fujiwara et al. (2004). We use data obtained from the vertical beam observations to derive the vertical profiles of the electron density and temperature over the ESR site. The methods for derivation of the ionospheric parameters (quantities) are briefly mentioned here.

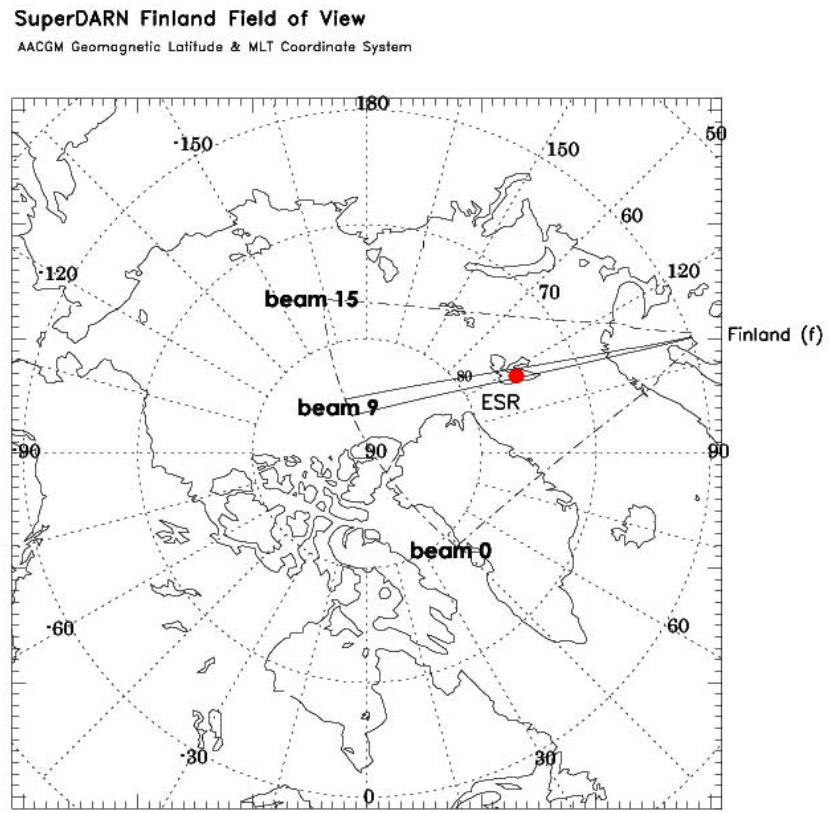

Fig. 2. Location of the ESR site at Longyearbyen (circle dot) and the field of view of the CUTLASS Finland radar in the geomagnetic latitude and MLT coordinate system. The field of view of the CUTLASS Finland radar consists of 16 beams (Beam 0-15), with Beam 9 over the ESR site.

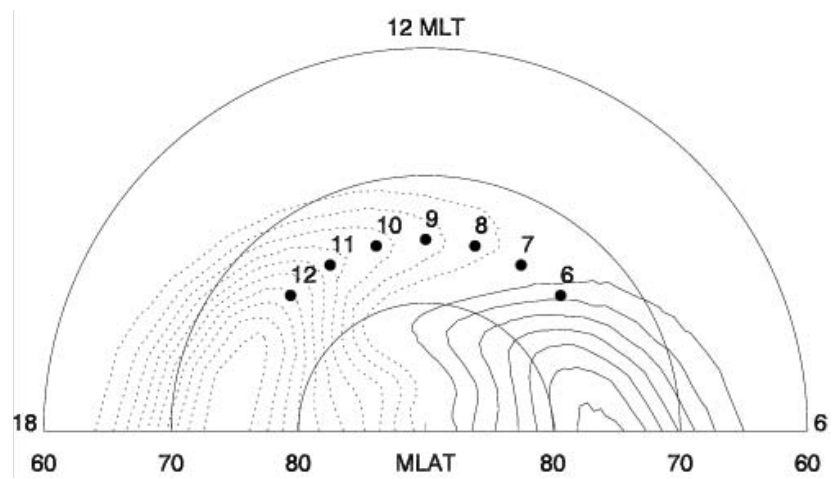

Fig. 3. High latitude electric potential calculated by using the Heppner-Maynard electric convection field model in the condition that IMF $B y$ and $B z$ are negative. The locations of the ESR site during 06:00-12:00 UT are marked by circle dots with numbers indicating the universal time.

The electron and ion temperatures, the electron density, and the ion velocity are derived from the ESR observations (4-beam scanning observations with 8-min antenna cycle). Full ion velocity vector, $\boldsymbol{V}_{i}$, is obtained by combining the three line-of-sight observations of the ion velocity, assuming that the velocity is uniform across the scattering volumes (spatial scale is $\sim 100 \mathrm{~km}$ ) and does not vary over a 3-beam scanning cycle (6 min). The electric field, $\boldsymbol{E}$, is derived from 


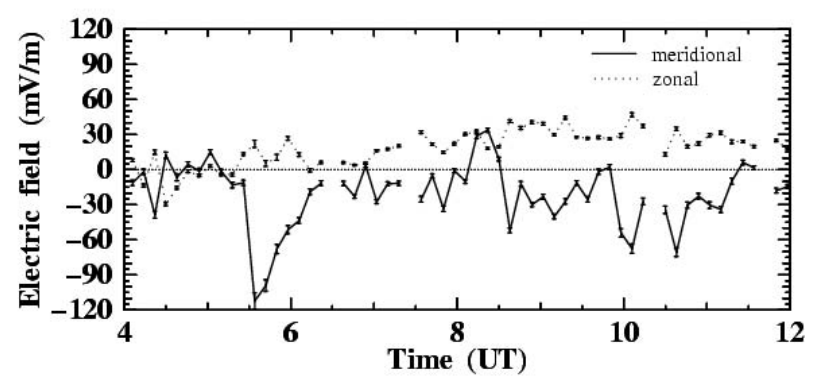

Fig. 4. The derived electric field during 04:00-12:00 UT on March 9, 1999 from the ion velocity at $278 \mathrm{~km}$ assuming that the $\boldsymbol{E} \times \boldsymbol{B}$ force drives motions of ions and electrons. The meridional (solid lines) and zonal (dotted lines) components of the electric field are positive toward the north and east, respectively.

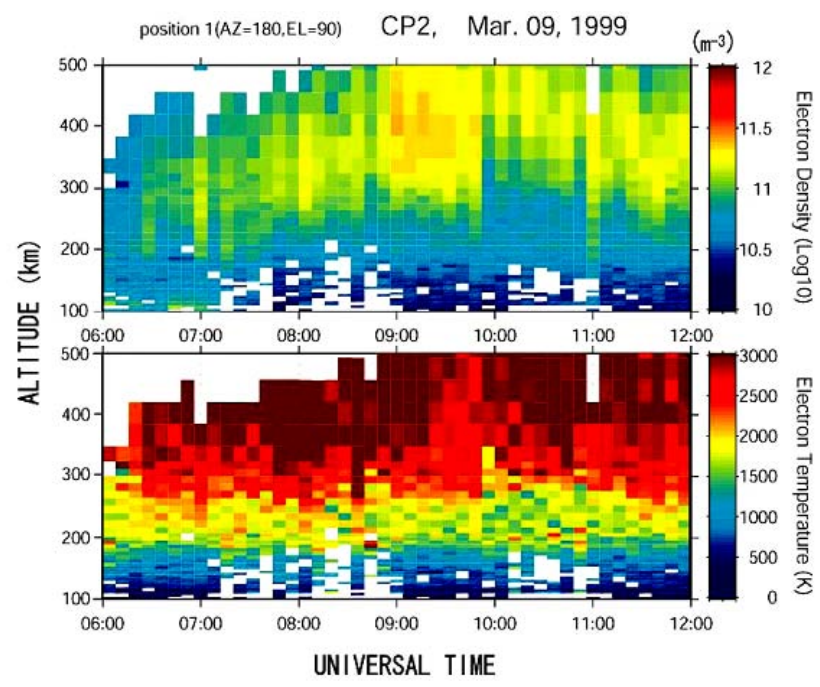

Fig. 5. The electron density (upper) and temperature (lower) derived from the ESR observations during 06:00-12:00 UT. Note that the electron density is displayed with logarithmic scale.

the ion velocity at about $278 \mathrm{~km}$ assuming that the $\boldsymbol{E} \times \boldsymbol{B}$ force drives motions of ions and electrons,

$\boldsymbol{E}=-\left(\boldsymbol{V}_{i} \times \boldsymbol{B}\right)_{278}$,

where $\boldsymbol{B}$ is the magnetic field. The value of the electric field is derived by combining the measurements of long pulse $\mathrm{F}$ region monostatic ion velocity with estimates of the magnetic field described by International Geomagnetic Reference Field (IGRF) model [International Association of Geomagnetism and Aeronomy Division I Working Group 1, 1987]. The errors of the electric field are estimated only from those of the ion velocity which are derived from IS spectrum fitting procedures. The errors due to spatial inhomogeneity are not considered here. The average absolute value of the electric field, $|\boldsymbol{E}|$, and the error, $\delta|\boldsymbol{E}|$, are 35.7 and $2.5 \mathrm{mV} / \mathrm{m}$, respectively in the period of 06:00-12:00 UT. The average of the relative error, $\delta|\boldsymbol{E}| /|\boldsymbol{E}|$, is estimated to be $6.9 \%$ in the present case. Furthermore, the average of the relative error of $E^{2}, \delta\left(E^{2}\right) / E^{2}(=2 \delta|\boldsymbol{E}| /|\boldsymbol{E}|)$, is $14 \%$.

Figure 4 shows the electric field obtained by using Eq. (1). The meridional (solid lines) and zonal (dotted lines) components of the electric field are positive toward the north and east, respectively. In the period of 06:00-12:00 UT, the electric field is almost in the south-east direction except for some intervals, in particular during 08:14-08:30 UT.

Figure 5 shows the electron density (upper panel) and temperature (lower panel) derived from the ESR observations. Note that the electron density is displayed with logarithmic scale in units of $\mathrm{m}^{-3}$. The electron density gradually increases with the course of the local solar time particularly above about $300 \mathrm{~km}$ altitude. The large increases in the electron density are seen during about 07:30-11:00 UT (08:3012:00 LST or 10:30-14:00 MLT at Longyearbyen) above about $300 \mathrm{~km}$ height with some cessations, which implies enhancements of precipitating soft electrons during this period. The enhancements of the electron temperature ( $>2500$ $3000 \mathrm{~K})$ are also seen above about $300 \mathrm{~km}$ altitude. The enhancements of the electron density and temperature almost correspond to each other.

Figure 6a-c show the strength of the electric field, $|\boldsymbol{E}|$, the Pedersen conductivity, $\sigma_{P}$, and the passive energy deposition rate per unit mass, $\sigma_{P} E^{2} / \rho$, derived from the ESR data, respectively, where $\rho$ is the atmospheric density obtained from the MSISE-90 empirical model (Hedin, 1991). The Pedersen conductivity, $\sigma_{P}$, is calculated from Eq. (2),

$\sigma_{P}=\frac{e n_{e}}{B}\left(\frac{v_{e n} \omega_{e}}{\omega_{e}^{2}+v_{e n}^{2}}+\frac{v_{i n} \omega_{i}}{\omega_{i}^{2}+v_{i n}^{2}}\right)$,

where $e$ is the electron electrostatic charge, $n_{e}$ is the electron or plasma density derived from observations, $v_{e n}$ is the collision frequency between electrons and neutrals, $v_{i n}$ is the collision frequency between ions and neutrals, $\omega_{e}$ is the electron cyclotron frequency, and $\omega_{i}$ is the ion cyclotron frequency. It is noted that the Pedersen conductivity is shown in the height range between 290 and $490 \mathrm{~km}$, and $\sigma_{P} E^{2} / \rho$ between 100 and $500 \mathrm{~km}$.

The neutral gas heating rate due to the electromagnetic energy deposition is described by using the electromagnetic energy transfer rate $\boldsymbol{J} \cdot \boldsymbol{E}$, where $\boldsymbol{J}=\boldsymbol{\sigma}(\boldsymbol{E}+\boldsymbol{U} \times \boldsymbol{B})$ is the electric current density, $\boldsymbol{U}$ is the neutral wind velocity, and $\boldsymbol{\sigma}$ is the electric conductivity tensor. We estimate the passive energy deposition rate, $\sigma_{P} E^{2}$, instead of $\boldsymbol{J} \cdot \boldsymbol{E}$. The quantity of $\sigma_{P} E^{2}$ gives the electromagnetic energy deposition rate in the absence of neutral wind effects. The contribution of the neutral wind to the energy deposition is discussed later. We present the neutral gas heating rate per unit mass $(\mathrm{W} / \mathrm{kg}), \sigma_{p} E^{2} / \rho$, which has information of the energy deposition to individual neutral particles. On the other hand, the heating rate per unit volume has relevant information for the total energy inputs into the ionosphere/thermosphere. Although $\sigma_{p} E^{2}$ shows the 


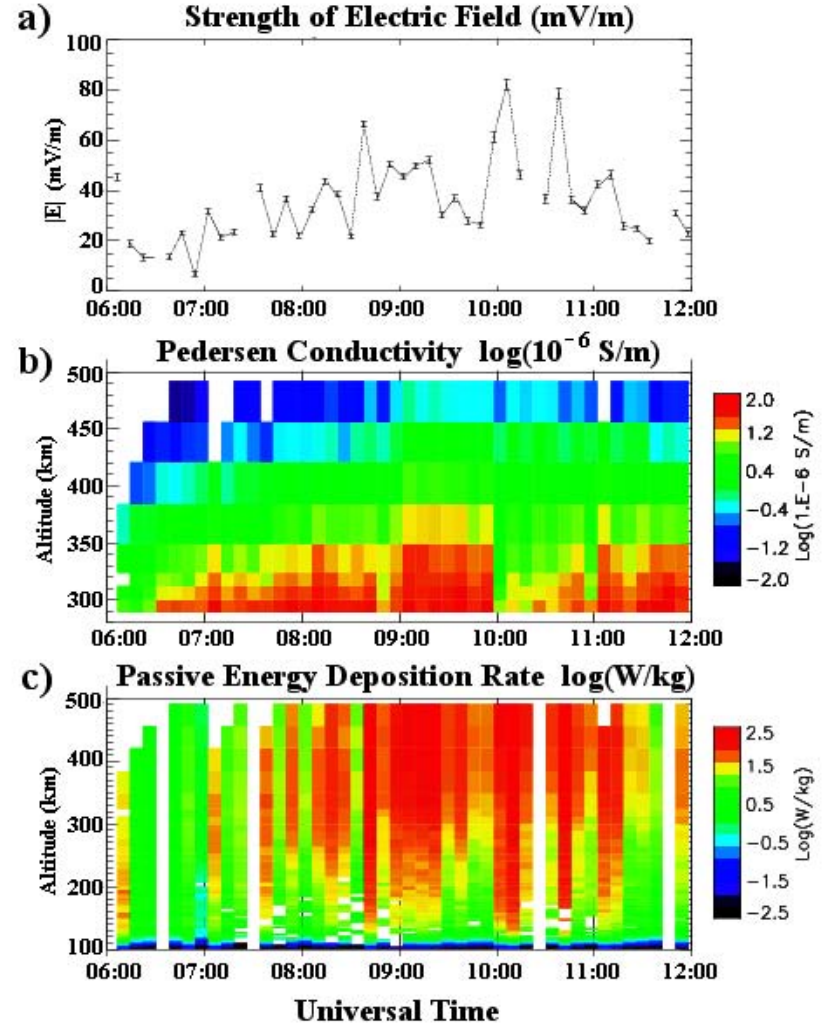

Fig. 6. (a) The strength of the electric field, $|\boldsymbol{E}|$, (b) the Pedersen conductivity above $290 \mathrm{~km}$, and (c) the passive energy deposition rate per unit mass, $\sigma_{P} E^{2} / \rho$, obtained from the ESR observations during 06:00-12:00 UT. $\boldsymbol{E}$ is the electric field, $\sigma_{P}$ is the Pedersen conductivity, and $\rho$ is the neutral mass density obtained from the MSISE-90 empirical model.

maximum value at around $120 \mathrm{~km}$ altitude depending on the Pedersen conductivity profile, $\sigma_{p} E^{2} / \rho$ shows large values in the upper thermosphere because of lower neutral density in the upper thermosphere than that in the lower thermosphere. Since it would be helpful to have quantities in units of $\mathrm{W} / \mathrm{m}^{3}$ for comparison with other studies, we show both the values in units of $\mathrm{W} / \mathrm{kg}$ and $\mathrm{W} / \mathrm{m}^{3}$.

There are some occurrences of large heating rates $(>150 \mathrm{~W} / \mathrm{kg})$ at the following approximate altitudes and times: e.g., $171 \mathrm{~W} / \mathrm{kg}\left(8.16 \times 10^{-10} \mathrm{~W} / \mathrm{m}^{3}\right)$ at $385 \mathrm{~km}$ and 08:38 UT, $177 \mathrm{~W} / \mathrm{kg}\left(4.53 \times 10^{-10} \mathrm{~W} / \mathrm{m}^{3}\right)$ at $421 \mathrm{~km}$ and 09:18 UT, $320 \mathrm{~W} / \mathrm{kg}\left(2.56 \times 10^{-10} \mathrm{~W} / \mathrm{m}^{3}\right)$ at $493 \mathrm{~km}$ and 10:06 UT, $249 \mathrm{~W} / \mathrm{kg}\left(1.19 \times 10^{-9} \mathrm{~W} / \mathrm{m}^{3}\right)$ at $385 \mathrm{~km}$ and 10:38 UT. The heating rate strongly depends on the electric field. In particular, the enhancements of the electric field between about 08:00 and 11:00 UT correlate well with the large heating rates. As seen in Fig. $6 \mathrm{~b}$, the Pedersen conductivity increases after about 09:00 UT corresponding to the enhancements of the electron density. The increases in the Pedersen conductivity also contribute to the large heating rates together with the enhanced electric field. at about $350 \mathrm{~km}$ alt.
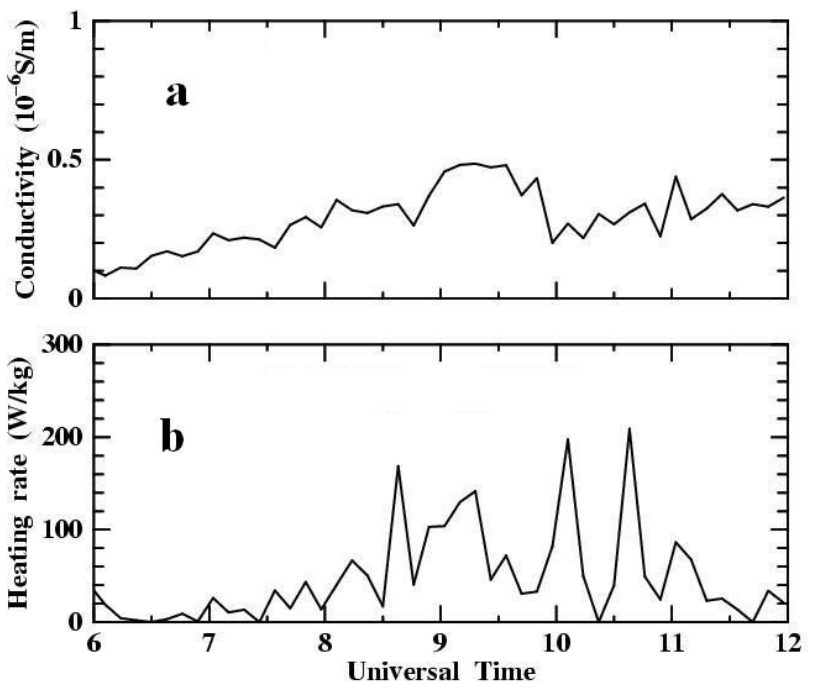

Fig. 7. (a) The Pedersen conductivity, $\sigma_{P}$ and (b) passive energy deposition rate, $\sigma_{P} E^{2} / \rho$, at about $350 \mathrm{~km}$ altitude obtained from the ESR observations during 06:00-12:00 UT. These are the same as those shown in Fig. 6 except for line plots at a specific height.

In order to clarify the enhancements of $\sigma_{p}$ and $\sigma_{p} E^{2} / \rho$, line plots of their variations at about $350 \mathrm{~km}$ altitude are shown in Fig. 7a and b, respectively. During about 08:3011:00 UT, enhancements of the heating rate are seen in Fig. 7b. Enhancements of the conductivity are also remarkable during about 09:00-09:50 UT as shown in Fig. 7a. The enhancements of the heating rate at 08:38, 10:06, and 10:38 UT are due to enhancements of the electric field, while the enhancements of the heating rate during about 09:0009:50 UT are due to enhancements of both the conductivity and electric field as mentioned above.

\subsection{CUTLASS observations}

CUTLASS is the HF radar system which covers a part of Super Dual Auroral Radar Network (SuperDARN) (Greenwald et al., 1995). CUTLASS has two radars at Finland and Iceland, and the details of the radar system are described by, e.g., Milan et al. (1997). The ionospheric plasma motions were obtained from the CUTLASS Finland radar observations during 06:00-12:00 UT (09:00-15:00 MLT at Longyearbyen). Unfortunately, the ionospheric back-scatter echoes were not detected during some time-intervals in this period because of strong ground back-scatter. Furthermore, no echoes were received by the Iceland radar. The CUTLASS Finland radar observes the line-of-sight ion Doppler motion using the 16direction beams with $3.5^{\circ}$ intervals over an azimuth sector of $52^{\circ}$. A special high space- and time-resolution scan mode was run, with the $30-\mathrm{km}$ range gates and with 2 -second scan in 32-s sweep over the 16 beams (from Beam 15 on the east of the field-of-view to Beam 0 on the west, see Fig. 2). In 


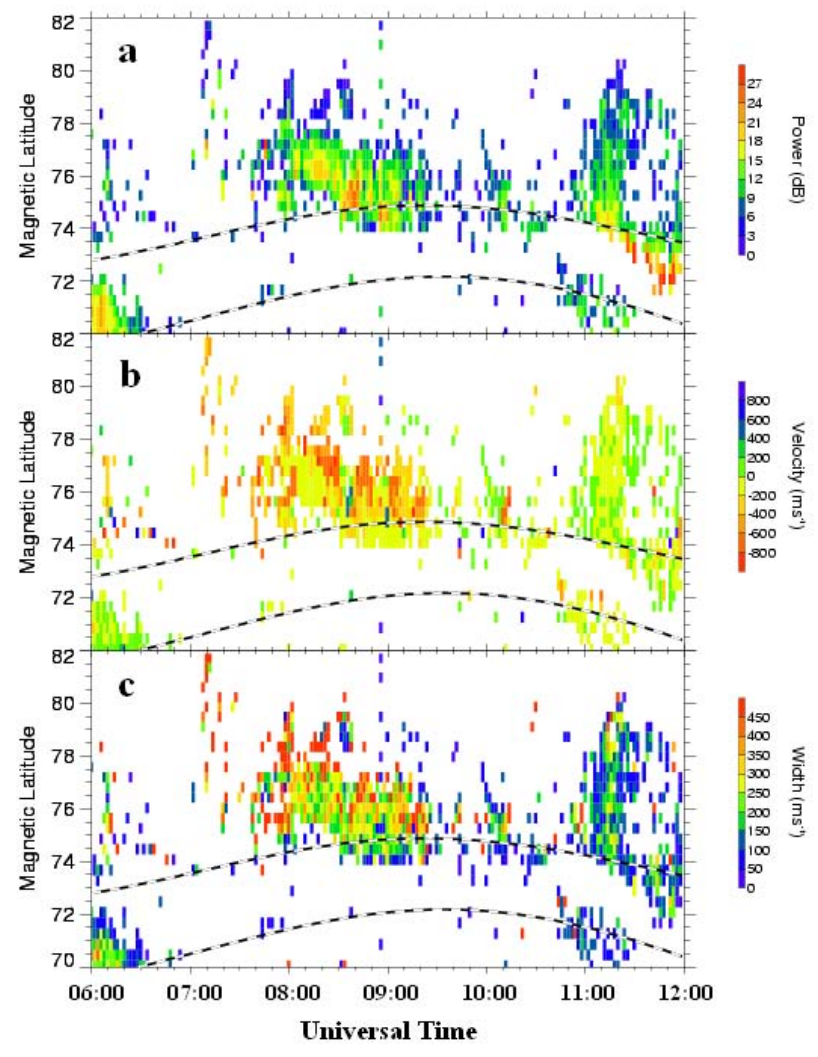

Fig. 8. (a) The echo power, (b) line-of-sight ion Doppler velocity, and (c) spectral width obtained from the Beam 9 observations during 06:00-12:00 UT (09:00-15:00 MLT at Longyearbyen) in the $70^{\circ}-82^{\circ}$ geomagnetic latitude range. The dashed lines denote the northward and southward edges of the Feldstein statistical auroral oval at $K p=4$. The positive (negative) values of the ion Doppler velocity indicate the motions toward (away from) the radar site, namely, equatorward (poleward) flows.

this study, we show the observational data from Beam 9 (over the ESR site) every 2 min.

Figures 8a-c show temporal variations of the echo power, line-of-sight ion Doppler velocity, and spectral width obtained from the Beam 9 observations, respectively. The ordinate and abscissa shown in Fig. 8 are the geomagnetic latitude and the universal time, respectively. The dashed lines in each panel show the locations of the poleward and equatorward edges of the Feldstein statistical auroral oval (Feldstein and Starkov, 1967) at $K p=4$ as a function of the universal time. Note that Longyearbyen is located at $75.12^{\circ}$ in geomagnetic latitude which is at the north of the statistical auroral oval during 06:00-12:00 UT. The positive (negative) values of the ion Doppler velocity indicate the motions toward (away from) the radar site, namely, equatorward (poleward) flows.

The signature of the pulsed ionospheric flows (PIFs) moving away from the radar site, i.e., the quasi-periodic variation of the high-speed plasma motion $(>600 \mathrm{~m} / \mathrm{s})$ away from the

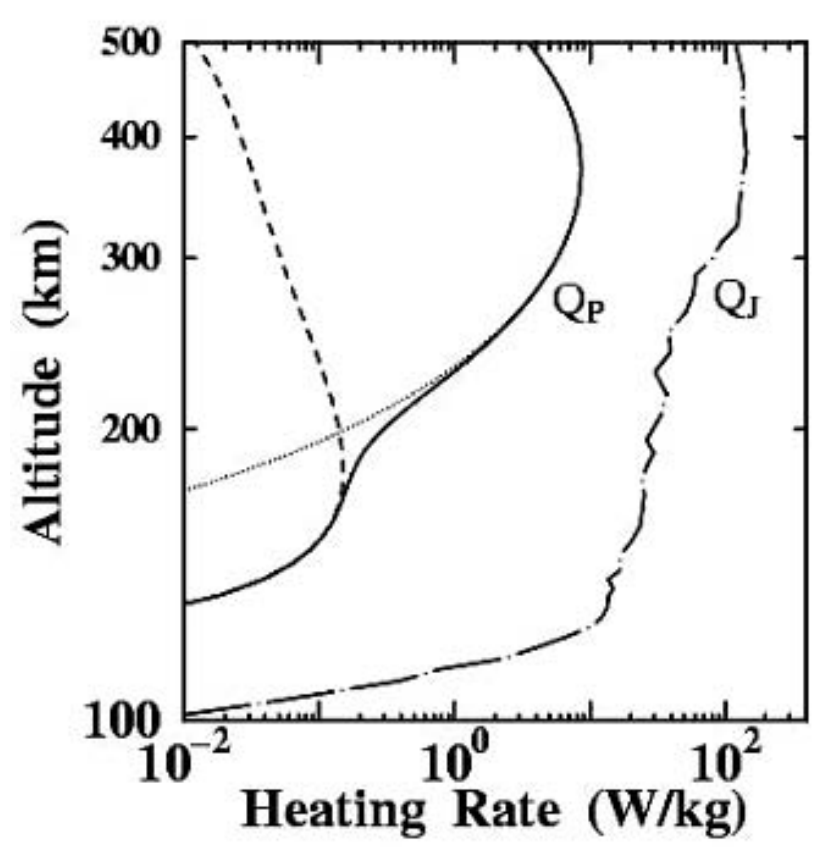

Fig. 9. The calculated heating rates $(\mathrm{W} / \mathrm{kg}$ ) due to precipitating electrons (dotted line), protons (dashed line), both particles (solid line labeled $\mathrm{Q}_{P}$ ), and $\sigma \mathrm{pE}^{2} / \rho$ at 09:10 UT derived from the ESR observations (dashed-dotted line labeled $\mathrm{Q}_{J}$ ).

radar site, is detected during about 07:30-10:10 UT (10:3013:10 MLT at and poleward of Longyearbyen) as seen in Fig. 8b. The recurrence rate seems to be about $10-20 \mathrm{~min}$. A similar variation is also seen in the spectral width (Fig. 8c). The high-speed plasma motions more than $800 \mathrm{~m} / \mathrm{s}$, which correspond to the electric field more than $36 \mathrm{mV} / \mathrm{m}$, observed during about 08:00-09:20 UT and at around 10:10 UT are consistent with large heating rates or strong electric field obtained from the ESR observation. Sudden and large change in the flow direction is seen at around 08:30 UT and $75^{\circ}$ geomagnetic latitude, corresponding to change in the electric field (form southward to northward) shown in Fig. 4. In addition, quasi-periodic enhancements of the ionospheric flows at around 07:50-08:00, 08:20-08:30, 08:30-08:50, 09:0009:10, 09:10-09:20, and 10:10 UT almost correspond to peaks of the electric field strength shown in Fig. 6a.

The PIF signature shown in the present study, namely, high-speed ion flows $(>600-800 \mathrm{~m} / \mathrm{s})$ with quasi-periodic variation $(\sim 10-20 \mathrm{~min})$ away from the radar site, is similar to those shown by, e.g., Provan et al. (1998, 1999), Neudegg et al. (1999), and Milan et al. (2000). Provan et al. (1998) identified the PIFs as being the ionospheric signature of the flux transfer events (FTEs) occurring at the dayside magnetopause. The strong echo power and wide spectral width are also observed at the same time during this period as shown in Fig. 8a and 8c, respectively. Baker et al. (1995) showed that the wide spectral width is one of the characteristics of the 
SuperDARN observation in the cusp region. Furthermore, the Defense Meteorological Satellite Program (DMSP) F11 satellite observed the cusp-type ion precipitation over Svalbard during 09:10-09:11 UT (see Maeda et al., 2002) when the wide spectral width is seen in Fig. 8c. The enhanced electron density and temperature observed with the ESR are also consistent with the ionospheric signature of the cusp region (e.g., Watermann et al., 1992). These suggest that Svalbard was located in or in the vicinity of the cusp region in the period of the high-speed ion flows (07:30-10:10 UT).

3.3 Comparison of the particle heating rate with the Passive energy deposition rate

In order to evaluate a relative importance of $\sigma_{p} E^{2} / \rho$ to the total energy deposition rate, we also estimate the particle heating rate in the cusp region with the calculation method presented by Rees $(1963,1982)$ using the atmospheric density obtained from the MSISE-90 model. The ionization rates due to precipitating electrons, $Q_{e}$, and ions, $Q_{i}$, are calculated by using the following Eqs. (3) and (4), respectively,

$$
\begin{aligned}
& \frac{Q_{e}}{F}=q_{z}=\frac{E_{0}}{\Delta \varepsilon} \frac{\rho(z)}{R} \lambda(Z / R), \\
& \frac{Q_{i}}{F}=q_{z}=\frac{E_{P}}{\Delta \varepsilon} \frac{\rho_{R}}{R} \frac{n(M)_{z}}{n(M)_{R}} \lambda(Z / R) f_{\text {ion }},
\end{aligned}
$$

where $F$ is the flux of incident electrons or ions per unit area, $E_{0}$ and $E_{p}$ are initial energies of incident electrons and ions, respectively, $\Delta \varepsilon$ is the energy loss per ionization, taken as $35 \mathrm{eV}, \lambda$ is the normalized energy dissipation distribution function, $\mathrm{Z} / \mathrm{R}$ is the fractional depth of penetration $(R$ is the maximum penetration depth of the electrons or ions). In Eq. (4) $\rho_{R}$ is the atmospheric density at the height of the maximum ion penetration, and $n(M)_{z}$ and $n(M)_{R}$ are the effective number densities at atmospheric depths of $z$ and $R$, respectively. See Rees $(1963,1982)$ and Millward et al. (1999) for details. Using the above ionization rates and the heating efficiency, $\varepsilon$, the atmospheric heating rate, $Q_{P}$, is calculated as (see Rees et al., 1983),

$Q_{P}=\frac{q(E) \cdot \varepsilon}{\rho} \Delta \varepsilon \cdot e \cdot F(E)=\frac{Q(E) \cdot \varepsilon}{\rho} \Delta \varepsilon \cdot e$.

Both precipitating ions and electrons are assumed to have Maxwellian flux spectra with energy ranges between 0 $20 \mathrm{keV}$ and $0-5 \mathrm{keV}$, respectively. Since Eq. (5) describes the heating rate for mono-energetic particles, we calculate integration of Eq. (5) over the energy range assuming above in both cases of electrons and ions. Based on the DMSP F11 satellite observation during 09:10-09:11 UT, we also assume the incident electrons with the maximum differential flux of $1.00 \times 10^{9} \mathrm{eV} \mathrm{cm}^{-2} \mathrm{~s}^{-1} \mathrm{sr}^{-1} \mathrm{eV}^{-1}$ at the mean energy of $0.1 \mathrm{keV}$ whilst ions with the maximum differential flux of $1.00 \times 10^{8} \mathrm{eV} \mathrm{cm}^{-2} \mathrm{~s}^{-1} \mathrm{sr}^{-1} \mathrm{eV}^{-1}$ at the mean energy of 1 $\mathrm{keV}$. These spectra have the same mean energies and similar maximum differential fluxes as those assumed by Millward et al. (1999). The work by Millward et al. (1999) was based on the DMSP satellite observations of the cusp region presented by Newell et al. (1991). Figure 9 shows the calculated heating rates $(\mathrm{W} / \mathrm{kg}$ ) due to precipitating electrons (dotted line), protons (dashed line), and both particle species (solid line labeled $Q_{P}$ ). The neutral gas heating efficiency is obtained from Rees et al. (1983). The profile of $\sigma_{P} E^{2} / \rho$ at 09:10 UT derived from the ESR observations is also plotted in Fig. 9 (dashed-dotted line labeled $Q_{J}$ ).

The peak altitude of the particle heating rate is $370 \mathrm{~km}$, which is almost the same as that of $\sigma_{P} E^{2} / \rho$ of $385 \mathrm{~km}$. The peak magnitude of the particle heating rate is only $8.62 \mathrm{~W} / \mathrm{kg}\left(5.11 \times 10^{-11} \mathrm{~W} / \mathrm{m}^{3}\right)$, much less than that of $\sigma_{P} E^{2} / \rho\left(144 \mathrm{~W} / \mathrm{kg}\right.$ or $\left.6.86 \times 10^{-10} \mathrm{~W} / \mathrm{m}^{3}\right)$. The precipitating soft electrons would contribute to heating through enhancement of the Pedersen conductivity rather than direct particle heating in the polar cap/cusp region of the upper thermosphere.

Wu et al. (1996) calculated the Joule and particle heating rates in the cusp region including effects of the modeled neutral wind with a one-dimensional satellite track model and the DE2 satellite particle data. They also showed that the Joule heating rate was greater than the particle heating rate at all altitudes below the satellite.

\section{Discussion}

From a thermospheric general circulation model simulation, Killeen and Roble (1986) showed that parcels transiting the dayside cusp were heated due to soft particle precipitation and this energy was then advected over the polar cap. In contrast to the present result, they estimated a small Joule heating rate because they assumed the small empirical convection electric field in the cusp region. In order to highlight the dynamical and thermodynamical effects of the localized cusp heating, they assumed large energy inputs due to precipitating soft particles 5-10 times larger than the typical ones (see Killeen and Roble, 1986). Their scenario for heating the polar cap thermosphere by means of the cusp energy will become more realistic when we consider the large electromagnetic energy deposition into the cusp region as shown in the present study.

We have estimated the passive energy deposition rate $\sigma_{p} E^{2}$ instead of the electromagnetic energy transfer rate $\boldsymbol{J} \cdot \boldsymbol{E}$ neglecting the effects of the neutral wind since there are no observational data for the dayside neutral wind at the F region height in the present study. We evaluate the importance of the neutral wind on the electromagnetic energy deposition with the ratio of $\boldsymbol{J} \cdot \boldsymbol{E}$ to $\sigma_{p} E^{2}$.

The ratio, $R$, of $\boldsymbol{J} \cdot \boldsymbol{E}\left(\sim \sigma_{p} \cdot(\boldsymbol{E}+\boldsymbol{U} \times \boldsymbol{B}) \cdot \boldsymbol{E}\right)$ to $\sigma_{p} E^{2}$ is represented as,

$$
R=\frac{\boldsymbol{J} \cdot \boldsymbol{E}}{\sigma_{P} E^{2}} \sim \frac{\sigma_{P}((\boldsymbol{E}+\boldsymbol{U} \times \boldsymbol{B}) \cdot \boldsymbol{E})}{\sigma_{P} E^{2}}=1+\frac{(\boldsymbol{U} \times \boldsymbol{B}) \cdot \boldsymbol{E}}{E^{2}} .
$$




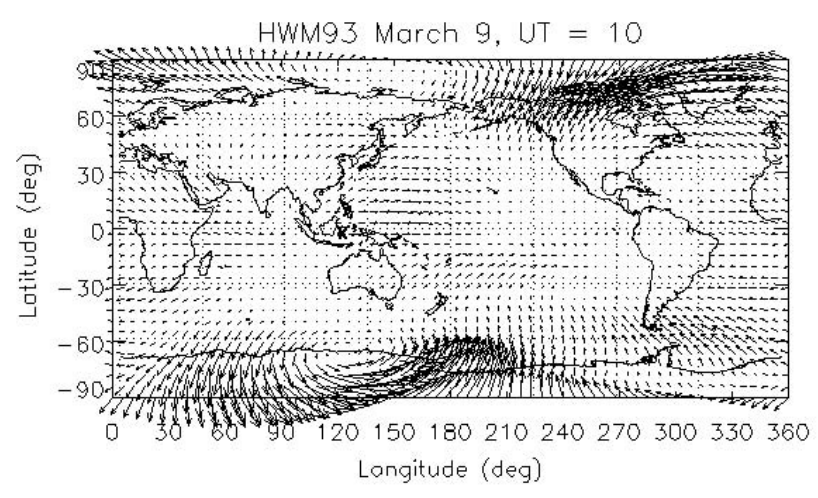

Fig. 10. Global pattern of the horizontal neutral wind derived from HWM-93 at $400 \mathrm{~km}$ altitude and 10:00 UT $\left(30^{\circ}\right.$ and $210^{\circ}$ longitudes are noon and midnight, respectively) on 9 March in the condition of $F_{10.7}=125$ and $A p=21$. The maximum arrow indicates the wind velocity of $359 \mathrm{~m} / \mathrm{s}$.
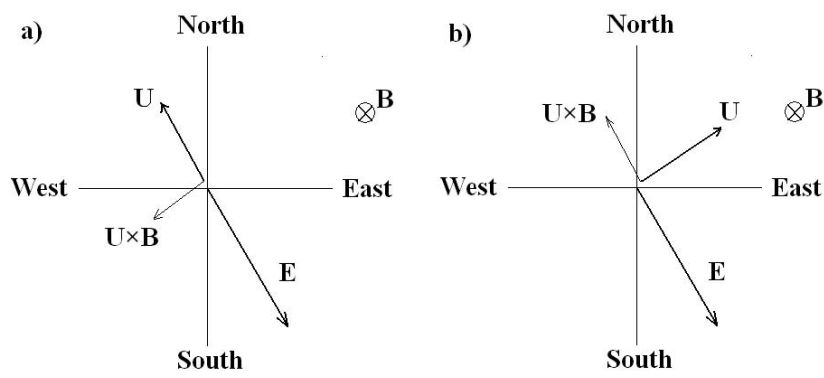

Fig. 11. Schematic illustration which shows a relationship between the neutral wind $\boldsymbol{U}$, electric field $\boldsymbol{E}$, and $\boldsymbol{U} \times \boldsymbol{B}$ in the northern high latitude region in cases; (a) $\boldsymbol{U}$ blows in the direction opposite to $\boldsymbol{E}$ and (b) $\boldsymbol{U}$ blows in the direction perpendicular to $\boldsymbol{E}$.

The neutral wind velocity, $\boldsymbol{U}$, seems to be mostly less than $500 \mathrm{~m} / \mathrm{s}$ in the polar cap/cusp region (e.g., Hays et al., 1984). In particular, the empirical neutral wind model of HWM-93 (Hedin et al., 1996) shows winds less than $300 \mathrm{~m} / \mathrm{s}$ in the northern dayside high-latitude region in the present condition. Figure 10 shows the global pattern of the horizontal neutral wind derived from HWM-93 at $400 \mathrm{~km}$ altitude and 10:00 UT $\left(30^{\circ}\right.$ and $210^{\circ}$ longitudes are noon and midnight, respectively) on 9 March in the condition of $F_{10.7}=125$ and $A p=21$. The maximum arrow indicates the wind velocity of $359 \mathrm{~m} / \mathrm{s}$. The meridional winds presented by HWM-93 have the northward component in the northern dayside highlatitude region. We therefore consider only the northward winds in the meridional direction in the following discussion.

Figure 11a and $\mathrm{b}$ are schematic illustrations which show relationships between the neutral wind $\boldsymbol{U}$, electric field $\boldsymbol{E}$, and $\boldsymbol{U} \times \boldsymbol{B}$. Since the electric field $\boldsymbol{E}$ was predominantly south-eastward in the present case, Fig. 11a and b show such a case. When $\boldsymbol{U}$ is north-westward (opposite to $\boldsymbol{E}$ ), $\boldsymbol{U} \times \boldsymbol{B}$ is perpendicular to $\boldsymbol{E}$ (Fig. 11a). In this case, $\boldsymbol{J} \cdot \boldsymbol{E}$ equals to $\sigma_{p} E^{2}$, namely $R=1$ (see Eq. 6). When $\boldsymbol{U}$ is north-eastward (perpendicular to $\boldsymbol{E}$ ), $\boldsymbol{U} \times \boldsymbol{B}$ is opposite to $\boldsymbol{E}$ (Fig. 11b). In this case, $\boldsymbol{U}$ contributes to reducing the electromagnetic energy deposition in the thermosphere most effectively.

As seen in Fig. 10, $\boldsymbol{U}$ tends to blow in the north-west direction during 07:00-13:00 LST (09:00-15:00 MLT at Longyearbyen) in the northern high-latitude region. The contribution of $\boldsymbol{U}$ for reducing the electromagnetic energy deposition seems to be small during this time interval. In general, the direction of the zonal winds may be variable depending on the local ion-drag and pressure gradient forces. Assuming that $\boldsymbol{U}$ is $500 \mathrm{~m} / \mathrm{s}$ (chosen as a rigid condition for the electromagnetic energy deposition in the present case, see, e.g., Hays et al., 1984) and that $\boldsymbol{B}$ is perpendicular to $\boldsymbol{U}$ with magnitude of $4.58 \times 10^{-5} T$ (based on the value calculated with the IGRF model which also presents the magnetic inclination of $82.1^{\circ}$ over Svalbard at $400 \mathrm{~km}$ altitude), the value of $\boldsymbol{U} \times \boldsymbol{B}$ is obtained to be $22.9 \mathrm{mV} / \mathrm{m}$. The zonal and meridional components of the electric field were about 47.0 (eastward) with error of 1.7 and -67.5 (southward) with error of $3.9 \mathrm{mV} / \mathrm{m}$, respectively, when the maximum passive energy deposition rate is obtained at 10:06 UT. When $\boldsymbol{U}$ contributes to reducing the electromagnetic energy deposition most effectively, namely, $\boldsymbol{U} \times \boldsymbol{B}$ is opposite to $\boldsymbol{E}$ ( $\boldsymbol{U}$ blows in the north-east direction when $\boldsymbol{E}$ is south-eastward), $R$ is estimated to be 0.722 from Eq. (6). Since $\sigma_{p} E^{2} / \rho$ is estimated to be about $320 \mathrm{~W} / \mathrm{kg}$ at 10:06 UT, the electromagnetic energy transfer rate is derived as $\boldsymbol{J} \cdot \boldsymbol{E} / \rho=\sigma_{p} E^{2} / \rho \cdot R=320 \cdot 0.722=231 \mathrm{~W} / \mathrm{kg}$ $\left(1.84 \times 10^{-10} \mathrm{~W} / \mathrm{m}^{3}\right)$. The electromagnetic energy more than about $70 \%$ of $\sigma_{p} E^{2} / \rho$ would deposit in and/or in the vicinity of the cusp region even when the strong neutral wind contributed to reducing the deposition rate.

From the CHAMP observations, Liu et al. (2005) showed that the MSISE-90 model underestimated the thermospheric density at $400 \mathrm{~km}$ altitude of about $20-30 \%$ in the cusp region while the observations outside the cusp region were in good agreement with the MSISE-90 predictions. The present estimation of the heating rates per unit mass may be overestimated due to the possible underestimation of the MSISE-90 model density. Owing to the underestimation of the thermospheric density by about $30 \%$ including the neutral wind effect, the electromagnetic energy transfer rate, $\boldsymbol{J} \cdot \boldsymbol{E} / \rho$, is estimated to be at lowest $178 \mathrm{~W} / \mathrm{kg}(=231 /(1+0.3)$ $\mathrm{W} / \mathrm{kg} \sim 1.43 \times 10^{-10} \mathrm{~W} / \mathrm{m}^{3}$ ) at 10:06 UT. Furthermore, if we consider the error for the electric field, the relative error of $\delta\left(E^{2}\right) / E^{2}$ is estimated to be $10.3 \%$ at 10:06 UT. Consequently, the possible $\boldsymbol{J} \cdot \boldsymbol{E} / \rho$ more than about 50 $60 \%(\sim 178 \times 0.897 / 320 \times 100$ or $178 \times 1.103 / 320 \times 100)$ of $\sigma_{p} E^{2} / \rho$ estimated from the ESR data is expected even when we consider the neutral wind effect, mass density ambiguity, and the error of the electric field.

Roble et al. (1987) presented the global mean total heating rates (including the solar, Joule, and auroral particle heating rates) per unit volume of $\sim 10^{5.1}$ and $\sim 10^{5.5} \mathrm{ergs} / \mathrm{gm} / \mathrm{s}$ at the solar minimum and maximum conditions, respectively (see 
Fig. 6 in their paper). These values correspond to the rates per unit mass of 13 and $32 \mathrm{~W} / \mathrm{kg}$, respectively, which are much less than the present result of $160(=178 \times 0.897)-196$ $(=178 \times 1.103) \mathrm{W} / \mathrm{kg}$. The heating rate of $160-196 \mathrm{~W} / \mathrm{kg}$ is also larger than the zonally averaged Joule heating rate with the maximum value of about $86 \mathrm{~W} / \mathrm{kg}$ in the auroral oval during the geomagnetically disturbed period (Maeda et al., 1989).

Wu et al. (1996) estimated the Joule and particle heating rates in the cusp region using a one-dimensional satellite track model with the DE2 satellite data in representative cases for active (19 September, 1981; $K p=5$ ) and quiet (23 September, 1981; $K p=1)$ geomagnetic conditions. The calculated Joule heating rate was greater than the particle heating rate at all altitudes below the satellite and the Joule heating peaked on the poleward side of the cusp/cleft precipitation region. Their estimates of the Joule heating rates were about $1.6 \times 10^{-7} \mathrm{ergs} \mathrm{cm}^{-3} \mathrm{~s}^{-1}$ in active and about $1.0 \times 10^{-7}$ ergs $\mathrm{cm}^{-3} \mathrm{~s}^{-1}$ in quiet geomagnetic conditions at $385 \mathrm{~km}$ altitude (see figures in their paper). Using the atmospheric density of the MSISE-90 model, the heating rates per unit mass are estimated to be about $1.3 \times 10^{3} \mathrm{~W} / \mathrm{kg}$ and $1.2 \times 10^{3} \mathrm{~W} / \mathrm{kg}$ in the two cases, respectively. In the geomagnetically active period, the particle heating rate and the Joule heating rate outside the cusp are also estimated to be about 26 and $75 \mathrm{~W} / \mathrm{kg}$, respectively, from their results.

The previous TGCM simulations seem to underestimate the Joule heating rate because of the fluctuation of the electric field as pointed by Codrescu et al. (1995), particularly in the cusp region. Codrescu et al. (1995) pointed out that their GCM calculations underestimated the Joule heating rate by about $30 \%$. On the other hand, the DE 2 and ESR observations indicate the importance of the Joule heating in the cusp or in the dayside polar cap region. The discrepancy of the estimated heating rates between $\mathrm{Wu}$ et al. (1996) and the present study seems to be mainly caused by the difference of the Pedersen conductivities between the works. Wu et al. (1996) calculated the ion composition and electron density to derive the Pedersen conductivity using the particle data obtained from the DE 2 observation, while we used the electron density profile obtained from the ESR observations and assumed ion composition from an empirical model. Because validation work on the satellite track model by Deng et al. (1995) showed that the Joule heating rate and electron density in the $\mathrm{F}$ region were overestimated comparing with those derived from the Chatanika radar observations, there is a possibility that Wu et al. (1996) overestimated the Pedersen conductivity and the Joule heating rate at the F region height. This suggests that the Pedersen conductivity is also important in addition to the fluctuation of the electric field for estimation of the Joule heating rate at the $\mathrm{F}$ region height.

The present study suggests large electromagnetic energy deposition rates in, and/or, in the vicinity of the cusp region in the upper thermosphere. It should be noted here that many previous studies, in particular GCM studies, used the time- averaged electric field (e.g., hourly averaged one) while the present results are obtained from the ESR data with fine timeresolutions. The present electromagnetic energy deposition rate also suggests the existence of the strong heat source in the dayside polar cap/cusp region of the upper thermosphere in association with the dayside magnetospheric phenomena of reconnections and flux transfer events. This heat source/energy input can be a possible source for generating disturbances in the thermosphere/ionosphere as well as TIDs originated from the Alvénic IMF- $B_{y}$ oscillations as shown by Prikryl et al. (2005).

\section{Conclusions}

In order to investigate electromagnetic energy inputs into the dayside polar cap/cusp region of the upper thermosphere, we have focused on significant thermospheric/ionospheric heating events on 9 March 1999, observed simultaneously with the ESR and the CUTLASS Finland radar.

During about 07:30-10:10 UT, the CUTLASS radar observed the signatures of the cusp plasma and the pulsed ionospheric flows (PIFs): the wide spectral width and the quasiperiodic variation (with the recurrence rate of $\sim 10-20 \mathrm{~min}$ ) of the high-speed plasma motion ( $>600-800 \mathrm{~m} / \mathrm{s}$ ) away from the radar site. The pulsed ionospheric flows are the ionospheric signature of the flux transfer events (FTEs).

The ESR observation showed the electron density and temperature enhancements above about $300 \mathrm{~km}$ during about 07:30-11:00 UT. Large passive energy deposition rates, $\sigma_{p} E^{2} / \rho$, of more than $150 \mathrm{~W} / \mathrm{kg}$ have been obtained during the period of the large electric field which sometimes showed values exceeding $40 \mathrm{mV} / \mathrm{m}$. In addition to the electric field enhancements, the Pedersen conductivity enhanced by the precipitating soft electrons also contributed to heating in the cusp region, while the direct heating due to the particle precipitation would be small. The maximum heating rate has been estimated as $\sigma_{p} E^{2} / \rho=320 \mathrm{~W} / \mathrm{kg}$ at about $493 \mathrm{~km}$ altitude at 10:06 UT. Even when we take into account the neutral wind effect, ambiguity of the neutral mass density, and the maximum error of the electric field, the possible $\boldsymbol{J} \cdot \boldsymbol{E} / \rho$ more than $160 \mathrm{~W} / \mathrm{kg}\left(\sim 50 \%\right.$ of $\left.\sigma_{p} E^{2} / \rho\right)$ is expected from the above heating rate.

The large thermospheric heating rates have been obtained from the ESR observations when the cusp and PIF signatures were observed with the CUTLASS radar. The present study suggests that a strong heat source would exist in the dayside polar cap/cusp region of the upper thermosphere in association with the dayside magnetospheric phenomena. The thermospheric heating as shown in this study will have significant impacts on the energetics and dynamics in the dayside polar cap/cusp region of the upper thermosphere. In order to understand physics of the polar thermosphere, more quantitative measurements of energy deposition are needed in the upper thermosphere (at the F region height). 
Acknowledgements. We are indebted to the Director and staff of EISCAT for operating the facilities and supplying the data. EISCAT is jointly funded by the Particle Physics and Astronomy Research Council (UK), Centre National de la Recherché Scientifique (France), Max-Plank Gesellschaft (F.R.G.), Suomen Akatemia (Finland), National Institute of Polar Research (Japan), Norges Almenvitenskapelige Forskningsrad (Norway), and Naturvetenskapliga Forskningsradet (Sweden). CUTLASS is deployed and operated by the University of Leicester, and is jointly funded by the UK Particle Physics and Astronomy Research Council, the Finnish Meteorological Institute, and the Swedish Institute of Space Physics. Thanks also to the staff of CDA web, and WDC-C2, Kyoto University for providing public WIND satellite data and geomagnetic indices, respectively. The IMAGE data was kindly supplied by the Auroral Observatory, University of Troms $\varnothing$. The empirical models of MSISE-90 and HWM-93 are provided by NSSDC/NASA. This work was supported in part by Grant-in-Aid for Scientific Research and the 21st Century COE program "Advanced Science and Technology Center for the Dynamic Earth" by the Ministry of Education, Science, Sports and Culture, Japan. The joint research program of the Solar-Terrestrial Environment Laboratory, Nagoya University also supported a part of this work.

Topical Editor M. Pinnock thanks two anonymous referees for their help in evaluating this paper.

\section{References}

Baker, K. B., Dudeney, J. R., Greenwald, R. A., Pinnock, M., Newell, P. T., Rodger, A. S., Mattin, N., and Meng, C.-I.: HFradar signatures of the cusp and low latitude boundary layer, J. Geophys. Res., 100, 7671-7696, 1995.

Basu, S. and Valladares, C.: Global aspects of plasma structures, J. Atmos. Sol.-Terr. Phy., 61, 127-139, 1999.

Codrescu, M.V., Fuller-Rowell, T. J., and Foster, J. C.: On the importance of E-field variability for Joule heating in the highlatitude thermosphere, Geophys. Res. Lett., 22, 2393-2396, 1995.

Codrescu, M. V., Fuller-Rowell, T. J., Foster, J. C., Holt, J. M., and Cariglia, S. J.: Electric field variability associated with the Millstone Hill electric field model, J. Geophys. Res., 105, 5265$5274,2000$.

Deng, W., Killeen, T. L., Burns, A. G., Johnson, R. M., Emery, B. A., Roble, R. G., Winningham, J. D., and Gary, J. B.: Onedimensional hybrid satellite track model for the Dynamics Explorer 2 (DE 2) satellite, J. Geophys. Res., 100, 1611-1624, 1995.

Feldstein, Y. I. and Starkov, G. V.: Dynamics of auroral belt and polar geomagnetic disturbance, Planet. Space Sci., 15, 209-229, 1967.

Fujii, R., Nozawa, S., Buchert, C. S., and Brekke, A.: Statistical characteristics of electromagnetic energy transfer between the magnetosphere, the ionosphere, and the thermosphere, J. Geophys. Res., 104, 2357-2366, 1999.

Fujiwara, H., Maeda, S., Suzuki, M., Nozawa, S., and Fukunishi, H.: Estimates of electromagnetic and turbulent energy dissipation rates under the existence of strong wind shears in the polar lower thermosphere from the EISCAT Svalbard Radar observations, J. Geophys. Res., 109, A07306, doi:10.1029/2003JA010046, 2004.
Greenwald, R. A., Baker, K. B., Dudeney, J. R., Pinnock, M., Jones, T. B., Thomas, E. C., Villain, J.-P., Cerisier, J.-C., Senior, C., Hanuise, C., Hunsucker, R. D., Sofko, G. J., Koehler, J., Nielsen, E., Pellinen, R., Walker, A. D. M., Sato, N., and Yamagishi, H.: DARN/SuperDARN: a global view of the dynamics of highlatitude convection, Space Sci. Rev., 71, 761-796, 1995.

Hays, P. B., Killeen, T. L., Spencer, N. W., Wharton, L. E., Roble, R. G., Emery, B. A., Fuller-Rowell, T. J., Rees, D., Frank, L. A., and Craven, J. D.: Observations of the dynamics of the polar thermosphere, J. Geophys. Res., 89, 5597-5612, 1984.

Hedin, A. E.: Extension of the MSIS thermosphere model into the middle and lower atmosphere, J. Geophys. Res., 96, 1159-1172, 1991.

Hedin, A. E., Fleming, E. L., Manson, A. H., Schmidlin, F. J., Avery, S. K., Clark, R. R., Franke, S. J., Fraser, G. J., Tsuda, T., Vial, F., and Vincent, R. A.: Empirical wind model for the upper, middle and lower atmosphere, J. Atmos. Terr. Phy. 58, 1421-1447, 1996.

Heppner, J. P. and Maynard, N. C.: Empirical High-Latitude Electric Field Models, J. Geophys. Res. 92, 4467-4489, 1987.

IAGA Division I Working Group 1, International geomagnetic reference field revision 1987, J. Geomag. Geoelectr., 39, 773-779, 1987.

Killeen, T. L. and Roble, R. G.: An analysis of the high-latitude thermospheric wind pattern calculated by a thermospheric general circulation model 2. Neutral parcel transport, J. Geophys. Res., 91, 11 291-11307, 1986.

Liu, H., Lühr, H., Henize, V., and Köhler, W.: Global distribution of the thermospheric total mass density derived from CHAMP, J. Geophys. Res., 110, A04301, doi:10.1029/2004JA010741, 2005.

Lühr, H., Rother, M., Köhler, W., Ritter, P., and Grunwaldt, L.: Thermospheric up-welling in the cusp region: Evidence from CHAMP observations, Geophys. Res. Lett., 31, L06805, doi:10.1029/2003GL019314, 2004.

Macdougall, J. W., Andre, A. D., Sofko, G. J., Huang, C.-S., and Koustov, A. V.: Travelling ionospheric disturbance properties deduced from Super Dual Auroral Radar measurements, Ann. Geophys., 18, 1550-1559, 2001, http://www.ann-geophys.net/18/1550/2001/.

Maeda, S., Fuller-Rowell, T. J., and Evans, D. S.: Zonally averaged dynamical and compositional response of the thermosphere to auroral activity during September 18-24, 1984, J. Geophys. Res., 94, 16869-16883, 1989.

Maeda, S., Nozawa, S., Sugino, M., Fujiwara, H., and Suzuki, M.: Ion and neutral temperature distributions in the E-region c. observed by the EISCAT Tromso and Svalbard radars, Ann. Geophys., 20, 1415-1427, 2002, http://www.ann-geophys.net/20/1415/2002/.

Maeda, S., Nozawa, S., Ogawa, Y., and Fujiwara, H., Comparative study of the high-latitude E-region ion and neutral temperatures in the polar cap and the auroral region derived from the EISCAT radar observations, J. Geophys. Res., 110, A08301, doi:10.1029/2004JA010893, 2005.

Matsuo, T., Richmond, A. D., and Nychka, D. W.: Modes of high-latitude electric field variability derived from DE-2 measurements: Empirical Orthogonal Function (EOF) analysis, Geophys. Res. Lett., 29, 1107, doi:10.1029/2001GL014077, 2002.

Milan, S. E., Yeoman, T. K., Lester, M., Thomas, E. C., and Jones, T. B.: Initial backscatter occurrence statistics from the CUT- 
LASS HF radar, Ann. Geophys., 15, 703-718, 1997,

http://www.ann-geophys.net/15/703/1997/.

Milan, S. E., Lester, M., Cowley, S. W. H., and Brittnacher, M.: Convection and auroral response to southward turning of the IMF: Polar UVI, CUTLASS, and IMAGE signatures of transient magnetic flux transfer at the magnetopause, J. Geophys. Res., 105, 15 741-15 755, 2000.

Millward, G. H., Moffett, R. J., Balmforth, H. F., and Rodger, A. S.: Modeling the ionospheric effects of ion and electron precipitation in the cusp, J. Geophys. Res., 104, 24 603-24 612, 1999.

Neudegg, D. A., Yeoman, T. K., Cowley, S. W. H., Provan, G., Haerendel, G., Baumjohann, W., Auster, U., Fornacon, K.-H., Georgescu, E., and Owen, C. J.: A flux transfer event observed at the magnetopause by the Equator-S spacecraft and in the ionosphere by the CUTLASS HF radar, Ann. Geophys., 17, 707-711, 1999, http://www.ann-geophys.net/17/707/1999/.

Newell, P. T., Meng, C.-I., Sanchez, E. R., Burke, W. J., and Greenspan, M. E.: Identification and observations of the plasma mantle at low altitude, J. Geophys. Res., 96, 35-45, 1991.

Ogawa, T., Buchert, S. C., Nishitani, N., Sato, N., and Lester, M.: Plasma density suppression process around the cusp revealed by simultaneous CUTLASS and EISCAT Svalbard radar observations, J. Geophys. Res., 106, 5551-5564, 2001.

Prikryl, P., Muldrew, D. B., Sofko, G. J., and Ruohoniemi, J. M.: Solar wind Alfvén waves: a source of pulsed ionospheric convection and atmospheric gravity waves, Ann. Geophys., 23, 401417,2005 ,

http://www.ann-geophys.net/23/401/2005/.

Provan, G., Yeoman, T. K., and Milan, S. E.: CUTLASS Finland radar observations of the ionospheric sigunatures of flux transfer events and the resulting plasma flows, Ann. Geophys., 16, 14111422, 1998, http://www.ann-geophys.net/16/1411/1998/.

Provan, G., Yeoman, T. K., and Cowley, S. W. H.: The influence of the IMF By component on the location of pulsed flows in the dayside ionosphere observed by an HF radar, Geophys. Res. Lett., 26, 521-524, 1999.

Rees, M. H.: Auroral ionization and excitation by incident energetic electrons, Planet. Space Sci., 11, 1209-1218, 1963.

Rees, M. H.: On the interaction of auroral protons with the Earth's atmosphere, Planet. Space Sci., 30, 463-472, 1982.
Rees, M. H., Emery, B. A., Roble, R. G., and Stamnes, K.: Neutral and ion gas heating by auroral electron precipitation, J. Geophys. Res., 88, 6289-6300, 1983.

Roble, R. G., Ridley, E. C., and Dickinson, R. E.: On the global mean structure of the thermosphere, J. Geophys. Res., 92, 87458758, 1987.

Shepherd, S. G., Ruohoniemi, J. M., and Greenwald, R. A.: Direct measurements of the ionospheric convection variability near the cusp/throat, Geophys. Res. Lett., 30, 2109, doi:10.1029/2003GL017668, 2003.

Thayer, J. P.: High-latitude currents and their energy exchange with the ionosphere - thermosphere system, J. Geophys. Res., 105, 23 015-23 024, 2000.

Thayer, J. P. and Semeter, J.: The convergence of magnetospheric energy flux in the polar atmosphere, J. Atmos. Sol.-Terr. Phy., 66, 807-824, 2004.

Wannberg, G., Wolf, I., Vanhainen, L.-G., Koskenniemi, K., Roettger, J., Postila, M., Markkanen, J., Jacobsen, R., Stenberg, A., Larsen, R., Eliassen, S., Heck, S., and Huuskonen, A.: The EISCAT Svalbard radar: A case study in modern incoherent scatter radar system design, Radio Sci., 32, 2283-2308, 1997.

Watermann, J., de la Beaujardière, O., and Newell, P. T.: Incoherent scatter radar observations of ionospheric signatures of cusp-like electron precipitation, J. Geomag. Geoelectr., 44, 1195-1206, 1992.

Weimer, D. R.: Improved ionospheric electrodynamic models and application to calculating Joule heating rates, J. Geophys. Res., 110, A05306, doi:10.1029/2004JA010884, 2005.

Wild, J. A., Cowley, S. W. H., Davies, J. A., Khan, H., Lester, M., Milan, S. E., Provan, G., Yeoman, T. K., Balogh, A., Dunlop, M. W., Fornacon, K.-H., and Georgescu, E.: First simultaneus observations of flux transfer events at the high-latitude magnetopause by the Cluster spacecraft and pulsed radar signatures in the conjugate ionosphere by the CUTLASS and EISCAT radars, Ann. Geophys., 19, 1491-1508, 2001, http://www.ann-geophys.net/19/1491/2001/.

Wu, Q., Killeen, T. L., Deng, W., Burns, A. G., Winningham, J. D., Spencer, N. W., Heelis, R. A., and Hanson, W. B.: Dynamics Explorer 2 satellite observations and satellite track model calculations in the cusp/cleft region, J. Geophys. Res., 101, 5329-5342, 1996. 